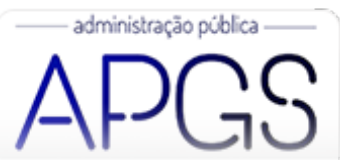

Administração Pública e Gestão Social ISSN: 2175-5787

apgs@ufv.br

Universidade Federal de Viçosa

Brasil

\title{
Mergulhando no desconhecido: observando controvérsias e estratégias na Fundação lluminação Silenciosa
}

Freitas Honorato, Bruno Eduardo; de Moura, Rodrigo Fernandes; Rodrigues da Silva, Everton Mergulhando no desconhecido: observando controvérsias e estratégias na Fundação lluminação Silenciosa

Administração Pública e Gestão Social, vol. 13, núm. 2, 2021

Universidade Federal de Viçosa, Brasil

Disponible en: http://www.redalyc.org/articulo.oa?id=351566014009

\section{(c) $(1) \Theta \theta$}

Esta obra está bajo una Licencia Creative Commons Atribución-NoComercial-SinDerivar 3.0 Internacional. 


\section{Mergulhando no desconhecido: observando controvérsias e estratégias na Fundação Iluminação Silenciosa}

\section{Diving into the unknown: observing controversies and strategies at the Silent Lighting Foundation}

Submergirse en lo desconocido: observando controversias y estrategias en la Fundación Iluminación Silenciosa

Bruno Eduardo Freitas Honorato

Redalyc: http://www.redalyc.org/articulo.oa?

Universidade Federal de Alfenas, Brasil $\mathrm{id}=351566014009$

brunoefh@gmail.com

Rodrigo Fernandes de Moura

Universidade Federal de Alfenas, Brasil

rohfermoura@gmail.com

Everton Rodrigues da Silva

Unifal-mg, Brasil

everton.rsilva@gmail.com

Recepción: 05 Mayo 2020

Aprobación: 30 Octubre 2020

Publicación: 01 Abril 2021

\section{Resumo:}

Contexto: Baseado em fatos e em dados fictícios, este caso de ensino narra a vivência de Jonas - aluno de Administração Pública da Universidade Federal de Alfenas - na Fundação Iluminação Silenciosa, uma organização de natureza espiritual, filantrópica e beneficente.

Dilema: Após seis meses de imersão no local Jonas observou contradições e conflitos na gestão da comunidade que não são decorrentes de falhas normativas, uma vez que sua estrutura organizacional é bem definida e comunicada internamente. Intrigado, Jonas aprofundou sua investigação e percebeu que as falas dos coordenadores e membros sugeriam que havia a necessidade de promover um diálogo sincero entre os atores organizacionais, a fim de que cada um pudesse conhecer melhor o universo de trabalho do outro e suas necessidades básicas, mas como cumprir essa tarefa?

Fechamento do caso: Este caso pretende estimular os estudantes a encontrar soluçóes criativas para este instigante dilema.

PALAVRas-ChaVE: estratégia organizacional, estratégia como prática, comunicação organizacional, organização sem fins lucrativos, comunidades intencionais.

\section{ABSTRACT:}

Context: Based on real facts and fictitious data, this teaching case narrates the experience of Jonas - a Public Administration student at the Federal University of Alfenas - at the Silent Illumination Foundation, an organization of spiritual, philanthropic and charitable nature.

Dilemma: After six months of immersion in the place, Jonas observed contradictions and conflicts in the management of the community, which are not due to regulatory failures, since its organizational structure is well defined and communicated internally. Intrigued, Jonas deepened his investigation and realized that the speeches of the coordinators and members suggested that there was a need to promote a sincere dialogue between the organizational actors, so that each one could better know the other's work universe and their basic needs, but how to accomplish this task?

Closing of the teaching case: This case aims to encourage students to find creative solutions to this exciting dilemma.

KEYWORDS: strategy as practice, organizational strategy, organizational communication, non-profit organization, intentional communities.

\section{Resumen:}


Contexto: Basado en hechos reales y en datos ficticios, este caso de enseñanza narra la experiencia de Jonas - alumno de Administración Pública de la Universidad Federal de Alfenas - en la Fundación Iluminación Silenciosa, una organización de base espiritual, filantrópica y de caridad.

Dilema: Después de seis meses de participación en el lugar, Jonas observó contradicciones y conflictos en la gestión de la comunidad, que no son ocasionados por fallas en su reglamento, ya que su estructura organizacional está bien definida y comunicada internamente. Intrigado, Jonas profundizó en su investigación y percibió que las conversaciones de los coordinadores y miembros sugerían que existía la necesidad de promover un diálogo sincero entre los participantes de la organización, con el fin de que cada uno pudiese conocer mejor el universo de trabajo del otro y sus necesidades básicas, pero, ¿cómo cumplir esta tarea?

Cierre del caso de enseñanza: Este caso pretende estimular a los estudiantes a encontrar soluciones creativas para este interesante dilema.

Palabras Clave: estrategia organizacional, organización sin fines de lucro, comunicación organizacional, estrategia como práctica, comunidades intencionales.

\section{ConteXtualização}

O presente caso, composto por dados reais e fictícios, narra a história vivenciada por Jonas, um jovem estudante do curso de Administração Pública na Universidade Federal de Alfenas - Campus Varginha (UNIFAL-MG). Jonas é guiado por uma vontade de investigar formas alternativas de organização coletiva alicerçadas em padrões e concepções diferentes das empresas convencionais. Esse desejo por novas experiências e aprendizados de alguma maneira levou-o ao grupo de pesquisa Organizações Outras (O2), sediado na universidade em que estuda. Durante uma atividade de campo, Jonas conheceu a Fundação Iluminação Silenciosa (FIS). A FIS é uma instituição (autonomeada comunidade) com fins não econômicos, de natureza espiritual, filantrópica e beneficente, situada na cidade de Baependi, nas montanhas de Minas Gerais, que se mantém por meio de doações espontâneas e presta serviços voluntários. Na primeira visita à FIS, a coordenadora espiritual expôs aos alunos do grupo de pesquisa que a comunidade precisava de auxílio em questões administrativas e seria bastante positivo se discentes do curso de Administração Pública e (ou) Economia pudessem colaborar. A comunidade experimentava dilemas na área administrativa devido ao crescimento inesperado no número de moradores, que ocasionou um incremento na demanda de diversos setores. Como as coordenações não estavam preparadas para essa complexa realidade gerencial, houve problemas de comunicação, de articulação entre elas e de falta de atualização no planejamento, gerando desafios no fluxo administrativo e na rotina cotidiana comunitária.

Desta forma, estabeleceu-se uma parceria entre a UNIFAL-MG e a FIS por meio do projeto de extensão "(Per)cursos organizacionais: do saber da experiência à experiência do saber na gestão de comunidades, associações e ecovilas", vinculado ao grupo de pesquisa $\mathrm{O} 2$, cuja dinâmica consistiu em visitas contínuas de $15 \mathrm{em} 15$ dias ao local, para observar e auxiliar nas dificuldades relatadas. Jonas foi um dos integrantes deste projeto e ficou seis meses imerso na FIS. Durante suas visitas, percebeu que haviam controvérsias em relação à gestão e à organização das unidades administrativas, envolvendo desde aspectos de autonomia decisória até a dificuldade de comunicação entre as coordenações.

\section{FundaÇÃo ILUMinaÇÃo SiLENCIOSA}

A base dos serviços da FIS envolve a cura e restauração da humanidade, da natureza e dos animais. A associação ampara e auxilia as pessoas da cidade e região por meio de atendimentos na área de saúde (psicologia, pediatria, florais e outras práticas terapêuticas) e do acolhimento de idosos e enfermos que precisam de cuidados especiais. O serviço altruísta é o fundamento basilar da instituição e a comunidade enxerga essa característica não como uma tarefa que visa apenas a melhoria das condições materiais de vida, mas como um estímulo para que o ser humano desenvolva o melhor de si em busca de sua autorrealização, elevando, assim, sua qualidade de vida e sua compaixão pelos seres. 
Desde sua fundação, em 2006, foram realizados mais de 9000 atendimentos médicos na própria FIS, além disso, cerca de 5000 presos, além de suas famílias e profissionais de segurança, foram atendidos em presídios de Baependi e municípios circunvizinhos.

Baependi é uma cidade com poucos recursos materiais, faltam empregos e uma boa parte da população consegue ocupação somente na época da colheita de café, que dura cerca de seis meses, e posteriormente fica ociosa, sem nenhuma remuneração. Essa também é a realidade de dezenas de localidades do sul de Minas Gerais. Almejando intervir positivamente nesse cenário regional, a FIS desenvolve as seguintes atividades: (1) distribuição de alimentos perecíveis (verduras, frutas e legumes) doados pelos sacolões da cidade e pela Central de Abastecimento de Belo Horizonte (CEASA Belo Horizonte); (2) visitas domiciliares semanais a famílias carentes, verificando e suprindo suas necessidades de saúde, alimentação e vestimenta, bem como realização de tratamento de saúde nos animais domésticos (gatos, cachorros e aves); (3) realização de cursos de formação em diversas áreas, como, por exemplo, aromaterapia, agricultura orgânica, panificação e bioconstrução.

A instituição oferece ainda assistência médica em três escolas da região, ampara pessoas em situação de rua por meio dos setores de Cura e Acolhimento, oferta diariamente cerca de 100 refeições vegetarianas gratuitas no centro de Baependi e cuida de animais (tratamento, cirurgia, castração e hospedagem de passagem) em seu setor Espaço dos Animais. Também é proprietária e coordena uma escola - Espaço Zen -, regulamentada pelo Ministério da Educação (MEC) e autorizada a funcionar na pré-escola e no fundamental I e II.

Esse amplo conjunto de atividades é posto em prática pelo desenho organizacional apresentado na Figura 1.

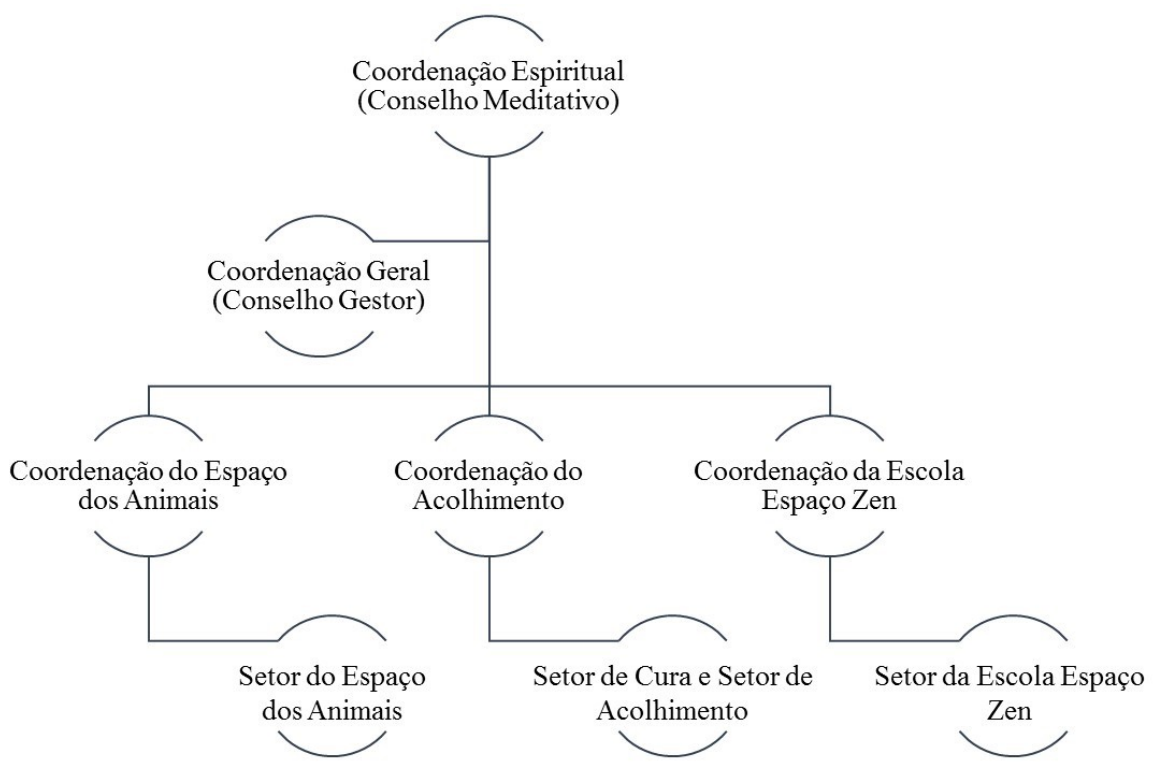

Figura 1: Organograma da Fundação Iluminação Silenciosa

A Coordenação Espiritual detém a palavra final sobre praticamente todas as deliberações da FIS, principalmente as de caráter financeiro e espiritual. À Coordenação Geral cabe observar o funcionamento das coordenações setoriais, auxiliando-as em questões técnicas e administrativas e reportando os resultados de suas ações para a Coordenação Espiritual. Além disso, essa coordenação é responsável pela alocação orçamentária, distribuição de recursos materiais e gestão de pessoas, para que os setores realizem suas tarefas.

Por fim, as coordenações específicas são responsáveis pelos seus respectivos setores. Elas não possuem autonomia financeira nem deliberativa, e os recursos necessários, como também os projetos e ações executadas, devem ser aprovados por ambos colegiados superiores. Cada coordenação setorial reúne-se com a Coordenação Geral mensalmente e trimestralmente com a Coordenação Espiritual, para deliberar sobre assuntos variados ligados às dimensões tática e operacional. 
A organização hierárquica descrita segue a clássica estrutura linear e é estratificada nos níveis estratégico, tático e operacional. É interessante mencionar que a FIS possui apenas três funcionários contratados que cuidam dos animais de grande porte resgatados para tratamento. A organização opera majoritariamente por meio de colaboradores voluntários e o fluxo de doações é responsável pela manutenção e ampliação dos serviços prestados.

\section{AS INQUIETAÇÕES DE JoNAS}

Desde o primeiro contato de Jonas com a FIS, passaram-se seis meses. Em seu relato de campo, Jonas descreveu sua primeira impressão sobre a FIS:

"Ao chegarmos na FIS fomos recebidos com carinho por algumas pessoas que vivem ali e estavam a nossa espera. Lembro-me da sensação de ansiedade que estava dentro de mim em busca de respostas e esclarecimentos que nem sabia ao certo quais eram. Ao anoitecer deste mesmo dia, tivemos uma reunião com as pessoas que fazem toda a estrutura da FIS funcionar, alguns moradores que vivem ali, nós do grupo de pesquisa e a coordenadora e guia espiritual da FIS. Neste momento descobrimos quais seriam as experiências que aguardariam por nós nos próximos dois dias e junto a isso, percebi que nosso papel ali - como estudantes de Administração Pública e Economia - seria de auxiliar em questões administrativas e organizacionais da FIS como organização não governamental e como forma alternativa de se organizar. Estes dois dias em que ficamos lá passaram muito rápido, consegui perceber muito pouco da estrutura e das pessoas envolvidas por trás da FIS, porém, um ar de incertezas, dúvidas e curiosidades sobre como tudo aquilo funciona ficou em mim, fazendo-me sentir que voltaria neste lugar mais vezes." (JONAS)

Ao conhecer a imensidão de atividades realizadas na FIS, Jonas teve grande interesse pelo lugar e pelas pessoas, aliado à vontade de conhecer profundamente como esta organização funciona e como poderia colaborar. No começo da jornada tudo estava confuso. Jonas sentia-se perdido no projeto de extensão, principalmente em relação às razões que o levavam a estar ali e surgiam em sua mente questões do tipo: "Será que estou atrapalhando aquelas pessoas ao invés de ajudar?”. Esses pensamentos emergiram principalmente devido à sensação de dúvida quanto à possibilidade de realmente poder fazer algo significativo na vida dos envolvidos na FIS e na sua organização.

Jonas expôs suas angústias e incertezas ao professor Thiago, seu orientador nesta experiência investigativa. Thiago aconselhou-o a não ter pressa e nem predeterminar algo fixo para se pesquisar, deixando que o processo de inserção e vivência na FIS mostrasse algum ou alguns caminhos. A recomendação era observar e manter-se aberto para um universo imensurável e desconhecido de possibilidades. Entretanto, a fim de orientar a postura investigativa de Jonas, Thiago sugeriu que ele observasse as contradições existentes naquele lugar, baseando-se na cartografia de controvérsias de Bruno Latour. Controvérsias são processos, incertezas compartilhadas, discordâncias ou concordâncias nas discordâncias, ou seja, é algo instável, um tipo de conflito ainda não resolvido, uma tensão entre atores e suas relações, algo de extrema complexidade.

Jonas questionou Thiago sobre porque utilizar a abordagem da cartografia de controvérsias, tendo recebido a seguinte resposta:

"Primeiramente porque as controvérsias são uma ótima forma para ver o social se formar, pois representam as tensões e conflitos antes da estabilização. Em segundo, porque compreendo que algumas relações existentes entre os seres envolvidos na FIS [humanos ou não] podem ser processos ainda instáveis, com diversas discordâncias e incertezas nas formas de se relacionar. Por fim, porque estar consciente destas instabilidades e de que forma elas são atuantes no cotidiano da FIS [por meio da observação e descrição realizada na cartografia das controvérsias] permitirá aberturas para repensar os modos de existência, as relações e as práticas vivenciadas na realidade da FIS.” (THIAGO) 


\section{No MEIO DO CAMINHO TINHA UMA PEDRA...}

Após ter consciência de como deveria ser sua observação (ou como não deveria ser), Jonas partiu para o processo de identificação das controvérsias. Notando o funcionamento da FIS, ele compreendeu que a mesma é dividida por coordenações e setores administrativos. Partindo daí, Jonas observou cada um desses setores e coordenações separadamente, criando um mapa mental para compreender a organização de forma sistêmica.

Este processo de investigação e conhecimento levou-o a uma conversa informal com um dos coordenadores do Espaço dos Animais. Durante o diálogo, foram relatados conflitos no gerenciamento do espaço, como por exemplo: (1) dificuldade de comunicação entre coordenações e entre coordenações e conselho geral da FIS, (2) problemas de autonomia financeira e de gestão de recursos diversos e (3) existência de muitas coordenações na FIS, sendo que suas verdadeiras funções não são claramente assimiladas (o que é a coordenação, para que serve e o que deve fazer?).

Ao mesmo tempo em que realizava esta vivência na FIS, Jonas cursava a disciplina de Gestão Estratégica Pública na UNIFAL-MG. Para realizar o trabalho final da disciplina ele deveria analisar como a noção de estratégia é vista e empregada numa instituição pública ou em uma organização não governamental. Ele notou que o caminho trilhado na pesquisa poderia conectar-se com a proposta de trabalho final pois as tensóes acima descritas levaram-no a querer compreender melhor como cada uma das coordenaçóes percebe sua estratégia, suas funções e interações, bem como a estratégia da FIS como um todo, para, enfim, compreender as diversas noções de estratégia acionadas no cotidiano organizacional.

Jonas percebeu que, com frequência, uma coordenação realizava o serviço que deveria ser feito por outra e também acontecia de as coordenações paralisarem diante de uma tarefa específica, pois ninguém sabia ao certo quem deveria assumi-la. $\mathrm{O}$ aspecto intrigante desses fatos, pensava Jonas, era que a sua razão não parecia estar na ausência de uma estrutura organizacional bem definida, dado que as normas eram conhecidas e reforçadas em reuniões sobre a gestão comunitária. A disciplina e a ordem eram valores importantes para a FIS, ambos faziam parte de sua filosofia espiritual.

Perplexo com suas descobertas e motivado a desvendar esse intrigante mistério, Jonas decide entrevistar três coordenadores da FIS (cada um vinculado a uma coordenação) e vários membros da comunidade.

\section{QuEM NÃO SE COMUNICA, SE “ESTRUMBICA”}

Um dos entrevistados foi Pablo, de 30 anos. Ele conheceu a FIS no México, por meio de um amigo, e vive lá desde março de 2017. Pablo atua como coordenador do Espaço dos Animais e disse ter tomado essa decisão após sentir o "chamado" durante um encontro de comunidades no México. Na data da entrevista, ele estava na coordenação há 7 meses. Sobre seu papel e suas estratégias, Pablo afirmou:

\footnotetext{
"Tenho dificuldade em enxergar a estratégia administrativa geral do Espaço dos Animais, pois não foi me dado a respectiva autonomia e acesso a estes dados. Eu compreendo que minha estratégia enquanto coordenador do Espaço dos Animais deveria estar voltada para formas de captação de recursos, doações e organização das atividades que devem ser realizadas. Existe dificuldade de união e comunicação entre as coordenações, pois existem tarefas que são realizadas na FIS que dependem da interconexão entre todas as coordenações e isso as vezes não acontece [fazendo gerar conflitos de agenda, execução e atribuição]. Um dos problemas que eu percebo, é a falta de comunicação correta. É necessário que as funções e delimitações das coordenações estejam claras e bem definidas para que cada coordenação possa compreender o que as outras estão fazendo e não ficarem se organizando e trabalhando da forma que bem entenderem." (PABLO)
}

A coordenadora do Setor de Acolhimento é Valéria Aparecida, de 70 anos. Para ela, o acolhimento deve ter total controle dos fluxos, ou seja, todas as pessoas que chegam e saem, e, além disso, deve entender o que tais pessoas estão vindo buscar, isto é, quais seus anseios. O Acolhimento, em sua perspectiva, envolve "muitas coisas dos diversos setores", para que todos possam estar bem e viver a experiência que têm que viver ali dentro. Quando questionada sobre sua visão em relação à estratégia desse setor, Jonas obteve a seguinte resposta: 
"É uma pergunta bem difícil, a gente vai fazendo aquilo que vai surgindo, então eu sinto que no meu setor precisa muito montar uma estratégia definida para o que fazer, tem que fazer, fica em uma situação que precisa de organização, eu tenho um perfil de prontidão e a prontidão com organização precisa de algo para unir” (VALÉRIA)

A ação em seu setor está baseada em uma lógica emergente, porém, para chegar a uma forma ideal, é necessário combiná-la com o planejamento formal, uma vez que o Acolhimento precisa ter uma visão ampla das demais unidades organizacionais. Por exemplo, o setor precisa estar atento ao refeitório, para verificar se o alimento está sendo servido corretamente, e ao dormitório, para verificar se as camas foram arrumadas e se atendem à demanda prevista. Devido ao número reduzido de colaboradores, a execução dessas funções pode aparentar - até mesmo causar - certa desorganização, completou Valéria.

Com intuito de aprofundar - ou como se diz em linguagem popular, de "escarafunchar" um pouco mais -, na controvérsia exposta por Pablo (falta de comunicação e união entre setores e coordenações), Jonas questionou se existem reuniões entre as coordenações. Valéria afirmou:

"Olha, ultimamente não estão ocorrendo estas reuniões entre coordenações e isso era algo que acontecia antes e precisa muito ser retomado. Sinto que sem essas reuniões falta confiança no grupo e clareza nos diálogos com as coordenações. As reuniões que acontecem com mais frequência são as do conselho gestor [ou coordenação geral] e uma vez por mês a do conselho meditativo [ou coordenação espiritual]." (VALÉRIA)

A última entrevistada foi Clara, de 40 anos, uma das coordenadoras da escola Espaço Zen. Jonas observou que ela aparenta estar sempre bem informada sobre tudo que acontece, além de muito disposta a incluir e auxiliar todos a conquistarem o que buscam. Clara disse que seu trabalho é muito dinâmico, que aprende fazendo, e que enxerga sua estratégia como líder da escola da seguinte maneira:

"A estratégia administrativa da escola, para as coisas funcionarem, trata da realização dos seguintes processos: estar observando as questóes legais que regem a escola; cuidar da questão curricular [quais conteúdos, quais disciplinas, quais professores são mais adequados]; mediar conflitos e saber lidar com os alunos [crianças] e com os pais. Em relação à estratégia financeira, precisamos de muita ajuda para encontrar parcerias ou editais que possam ajudar a manter a escola em funcionamento [haja vista que o serviço prestado é gratuito]. Por eu ter ficado cinco meses como coordenadora geral, tenho uma visão mínima da estratégia do todo [FIS], pois esta coordenação participa de várias reuniões administrativas dos mais diversos níveis. Esse conhecimento do todo depende muito do setor em que você está, ou seja, tem como você viver aqui dentro estando em um setor e não compreender o todo funcionando.” (CLARA)

Jonas também questionou-a em relação à controvérsia relatada por Pablo, e Clara relatou:

\footnotetext{
"Quando cheguei na FIS achava que as pessoas faziam as coisas sem ter claro quais as tarefas delas [sem ter funções definidas], porém, com o tempo percebi que isso não é o mais importante e sim a forma de convívio em grupo e com os outros, que o importante é estar bem com os outros e fazer os serviços fluírem de forma harmoniosa. A comunicação é algo sempre complicado em qualquer lugar e grande parte dos conflitos aqui são recorrentes principalmente por situaçóes não resolvidas. A comunicação entre coordenações precisa sim melhorar para poder contornar estas dificuldades.” (CLARA)
}

\section{DiAlogando COM A COMUNIDADE}

Será que os desafios mencionados pelas coordenações são os mesmos percebidos pelos membros da comunidade? Esta pergunta ressoava em Jonas, cotidianamente. Ele decidiu que o caminho seria entrevistar os membros imersos diariamente na rotina da FIS. Após conversar com 30 voluntários e analisar o conteúdo desses diálogos, Jonas notou que existem ponderações que se repetem, formando padrões expressos pelas seguintes falas descritas na Figura 2. 


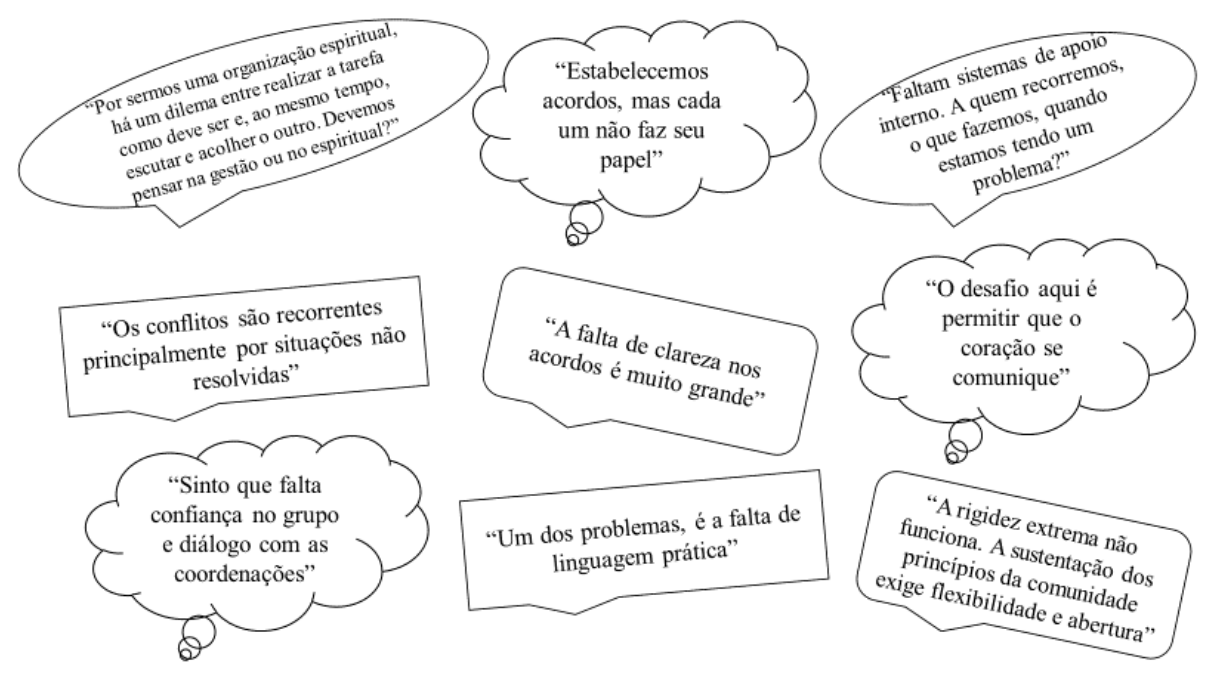

Figura 2: Percepção dos membros da FIS

Para Jonas, estas falas representaram a descoberta de um verdadeiro tesouro. Ele sente ter tocado a causa autêntica das controvérsias manifestadas pela comunidade. Ávido por compartilhar sua descoberta, Jonas apresenta-as para a Coordenação Geral. Sensibilizados pela história contada, os coordenadores relatam o que ouviram à Coordenação Espiritual, que decide, imediatamente, convocar uma reunião geral, requerendo a presença de todos os membros e coordenadores. A coordenadora espiritual solicitou que Jonas expusesse os conflitos e problemas descritos e propusesse alternativas e soluções para os mesmos.

\section{Dilema do CASO}

Após vivenciar a realidade da FIS durante 6 meses, Jonas necessita redigir um relatório e elaborar uma apresentação para a comunidade, descrevendo seus principais achados e apontando soluções para as controvérsias encontradas. Jonas fica paralisado: num piscar de olhos surgem as opiniões e diagnósticos anunciados pelos entrevistados, como se fossem fantasmas assombrando-o na madrugada. Era noite e ele decide interromper o trabalho e sair para caminhar e espairecer um pouco. No dia seguinte, um impulso de confiança o faz perceber que não há como propor soluções sem conhecer o cotidiano organizacional, caso contrário incidirá no erro comum de apresentar soluções que não foram cocriadas pela comunidade envolvida. Ciente de que no próprio estatuto que rege o funcionamento da FIS já estão definidas claramente as atribuições de cada coordenação e as ações cotidianas a serem realizadas - ou seja, a estrutura organizacional da instituição é bem definida e comunicada em reuniões internas -, Jonas se questiona, intensamente: Por quais motivos continuam havendo conflitos de comunicação e de divisão de tarefas entre as coordenações?

Para responder a essa pergunta, Jonas compreende que é importante conhecer com profundidade o cotidiano dos coordenadores e de seus membros, para que cada um enxergue a FIS como um coletivo integrado. Em sua visão, as falas dos coordenadores e membros sugerem que há a necessidade de promover um diálogo sincero entre os atores organizacionais, a fim de que cada um possa conhecer melhor o universo de trabalho do outro e suas necessidades básicas, mas como cumprir essa tarefa? 


\section{Notas DE Ensino}

\section{Objetivos educacionais}

- Compreender a importância de se considerar a percepção dos atores imersos no cotidiano organizacional (sensemaking) como fonte de informação relevante para os diagnósticos de problemas gerenciais;

- Compreender a importância de uma comunicação interna eficaz para a construção de uma estratégia coletiva para a organização;

- Estimular a reflexão crítica sobre as limitações dos modelos gerenciais ensinados nos livros-texto de Administração e Administração Estratégica, revelando a natureza contextual e situacional do conhecimento gerencial, seu aspecto cultural e sociotécnico.

\section{Fonte de obtenção dos dados}

Os dados utilizados neste caso de ensino foram obtidos por meio de entrevistas semiestruturadas - registradas por gravador de áudio - realizadas com os coordenadores e membros de cada setor da FIS. Esses diálogos aconteceram na própria instituição no período de fevereiro a julho de 2018. A base do caso foi constituída por dados reais, acrescidos de outros fictícios.

\section{Utilização do caso}

O caso é destinado aos alunos do curso de Administração e Administração Pública e Gestão Social, na graduação e pós-graduação, e pode ser aplicado: i) em disciplinas introdutórias como Introdução à Administração e Teoria Geral da Administração, ressaltando os aspectos referentes à divisão de tarefas e à visão dos atores imersos no cotidiano organizacional; ii) em disciplinas voltadas para a Comunicação Organizacional, reforçando aspectos ligados à comunicação interna das organizações e suas peculiaridades; iii) em disciplinas do campo da Estratégia Organizacional ou Gestão Estratégica, que se propóem a compreender a estratégia como uma construção coletiva que emerge a partir da tensão que se estabelece entre uma pluralidade de visões acionadas no cotidiano organizacional e também a debater a relevância da comunicação na consolidação da estratégia organizacional. Nesse sentido, acreditamos que a natureza do caso alinha-se, mais especificamente, aos debates do campo da Estratégia como Prática; e, por fim, iv) em disciplinas voltadas à discussão da Teoria Organizacional, enfocando os desafios na construção de formas de gestão participativas e não convencionais. $\mathrm{O}$ caso pode ser também utilizado em cursos de extensão para um público variado, especialmente os gestores sociais.

Esperamos que este caso de ensino contribua para fazer do ensino de administração uma práxis afeita ao estímulo do pensamento crítico dos alunos. $O$ caso de ensino pode e deve ser pensado como uma alternativa pedagógica contemporânea de dinamização do ensino, mas deve ser igualmente pensado como um instrumento à disposição dos docentes para revelar novas lógicas gerenciais e realizar uma saudável problematização (na sala de aula) sobre a adequação dos conhecimentos presentes nos manuais de administração ao contexto sócio-histórico em que são implantados. 


\section{Sugestões para utilização do caso de ensino}

- Entregue o caso para os alunos e peça-os para fazer uma leitura individual. Essa leitura pode ser durante a aula ou antes da mesma, dependendo da disponibilidade de carga horária do docente;

- Oriente a leitura: solicite a cada um que faça marcações no texto e traga eventuais dúvidas escritas;

- Leia os objetivos de aprendizagem e deixe-os bem claros. Procure relacionar tais objetivos com os debates e leituras teóricas já realizadas na disciplina;

- Depois da leitura individual, o docente deve dividir a turma em pequenos grupos (com 3 a 4 integrantes, se possível). Antes, caso algum discente queira comentar algo sobre o caso, abra um breve espaço para este fim;

- Após a divisão de grupos, entregue as "Questões para Discussão" e, se achar conveniente, indicações de leituras teóricas complementares citadas no item "6.8. Discussão";

- Explique a dinâmica da atividade: cada grupo deve conversar sobre o caso e entregar a resposta das questóes por escrito. $\mathrm{O}$ docente deve estar presente em todo o processo de discussão. Ele deve circular entre os grupos, permanecer aberto e disponível para tirar dúvidas, provocar debates e incitar os discentes a aprofundarem suas próprias interpretações. No item "Discussão" há indicações mais precisas sobre como o docente pode provocar os debates;

- Em seguida, organize a sala em um grande círculo e inicie um diálogo sobre o caso.

No início do processo de trabalho com os grupos, é bastante relevante que o docente enfatize a importância de os estudantes se transportarem para a realidade do caso e se sentirem protagonistas da narrativa apresentada. Um dos objetivos centrais do método do caso, é que os alunos tenham uma vivência o mais próxima possível da situação real. Por essa razão, não há necessidade de o docente mediar a "resolução" do caso, seguindo um rigor metodológico, como num processo de pesquisa convencional. É a suspensão desse rigor que tende a possibilitar a aproximação do estudante com o mundo tal como ele é, muito embora a "resolução" do caso deva ser pensada em articulação com os conceitos teóricos apresentados como suporte para o debate.

Recomenda-se, a nosso ver, que o docente estimule que o estudante seja um sujeito ativo no processo de aprendizagem, o que significa dizer que o mesmo deve ser estimulado "a sair da submissão e da passividade" (Nicolini, 2003, p. 51). O aprendiz deve "ser incentivado a romper paradigmas, a criar, a ousar" (Nicolini, 2003, p. 50), deixando de ser meramente estimulado a dar respostas prontas.

O que percebemos a partir de nossa experiência profissional é que o uso do método do caso requer certa abertura do docente para rever o processo habitual de ensino-aprendizagem, tarefa desafiadora que demanda também o comprometimento discente, afinal, tornar a sala de aula um ambiente mais inovador e dinâmico não é uma tarefa exclusiva do docente.

\section{Questões para discussão}

- Quais os conflitos descritos por Jonas após 6 meses de imersão na FIS? Como expressá-los, sinteticamente, numa controvérsia central? Além disso, diante do intrigante caminho percorrido por Jonas, qual é, objetivamente, o problema apresentado pelo caso?

- A abordagem da estratégia como prática tem a preocupação de compreender as organizações in situ e valorizar a subjetividade dos indivíduos no fazer organizacional. Como essa abordagem pode contribuir para solucionar o problema de comunicação interna e de divisão de funções e tarefas apresentado no caso?

- Quais ações podem ser adotadas para resolver o problema de comunicação e divisão de tarefas entre as coordenações? 
- Como a abordagem da estratégia como prática pode auxiliar na definição de um plano estratégico participativo, que nasça de "baixo para cima", de modo que os sujeitos envolvidos possam se sentir construtores ativos dos projetos sociais da FIS?

\section{Discussão}

\section{Primeira questão:}

$\mathrm{Na}$ seção 4, nosso personagem principal dedica-se a identificar a controvérsia que está gerando a desestabilização organizacional apresentada no caso. Seu ponto de partida é a identificação de conflitos e insatisfações. Num primeiro momento, em um diálogo informal, Jonas descreve três conflitos: (1) dificuldade de comunicação entre coordenações e entre coordenações e conselho geral da FIS, (2) problemas de autonomia financeira e de gestão de recursos e (3) existência de muitas coordenações, sendo que suas verdadeiras funções não são claramente assimiladas. Sua percepção é ampliada pelas entrevistas subsequentes. Pablo fala de uma deficiente comunicação vertical e horizontal; Valéria, com seu perfil de prontidão, reclama uma conexão com o propósito geral da FIS; e Clara enfatiza o impacto negativo no clima organizacional, quando há situações não resolvidas e falhas na comunicação. Os membros da FIS, por sua vez, discorrem sobre a falta de clareza nos acordos; a falta de sistemas internos de apoio; a necessidade de construir um ambiente que propicie um agir com eficiência e acolhimento e escuta do outro, valores importantes para a FIS, em função de sua natureza espiritual; e sobre a necessidade de desenvolver processos comunicativos empáticos entre as coordenações e com a coordenação geral.

Este mapa de conflitos pode ser sumariamente descrito por uma controvérsia central: há uma falta de compreensão das atribuições de cada coordenação e de suas interdependências, razão para inúmeros conflitos de funções, comunicativos e decisórios.

É razoavelmente frequente que, a partir da perspectiva clássica da teoria organizacional, ao deparar-se com esse conjunto de conflitos, elabore-se o diagnóstico de carência de uma estrutura organizacional bem definida. Acontece que, como relatado por Jonas, o aspecto intrigante do caso é que a comunidade parece conhecer bem as normas e a estrutura organizacional, pois a disciplina e a ordem são valores importantes para a FIS. Essa era a pedra no meio do caminho de Jonas. Algo parecia não fazer sentido. A observação continuada no campo de pesquisa sugere ao nosso protagonista que embora haja uma estrutura organizacional bem definida, ela não é reconhecida como legítima pelos atores. Essa é uma questão interessante a ser explorada. Assim, um dos importantes objetivos educacionais do caso é apresentar e explorar com os estudantes essa perspectiva analítica bastante útil de ser acionada diante de problemas organizacionais. O mistério de Jonas, para ser desvelado, exigirá dos estudantes um melhor conhecimento sobre a percepção dos membros da comunidade, sobre como as normas são apropriadas e negociadas no cotidiano e sobre quais conflitos surgem dessa mediação. O problema não está na fragilidade burocrática da organização, mas na percepção e apropriação feitas dos dispositivos burocráticos, ou seja, nos consensos e dissensos partilhados coletivamente.

\section{Segunda questão:}

Esta pergunta tem o propósito de extrair uma síntese conceitual das contribuições da estratégia como prática (ou S-as-P, sigla correspondente à expressão strategy as practice no idioma inglês) no caso em questão.

Pode-se dizer que a $S$-as-P define seu foco analítico no strategizing. Deste modo, a estratégia não é definida como uma propriedade das organizações (um atributo que as organizações possuem), mas algo que seus membros fazem e o strategizing é propriamente o resultado (materialidade das ações) da inter-relação entre práxis (ou prática, no singular), práticas (practices) e praticantes (Jarzabkowski, 2005; Jarzabkowski, Balogun, 
\& Seidl, 2007; Whittington, 2006). Por práxis (ou atividade) deve-se entender o trabalho realizado pelos estrategistas ao se fazer a estratégia, ou seja, é a “. . é a estratégia como fluxo da atividade organizacional que incorpora conteúdo e processo, intenção e emergência, pensamento e ação e assim por diante, como recíprocos, inter-relacionados e frequentemente partes indistinguíveis de um todo quando observados de perto" (Jarzabkowski, 2005, p. 8). O termo práticas refere-se a três tipos possíveis de ação: (1) as administrativas, materializadas pelos sistemas de controle, ferramentas de planejamento, etc.; (2) discursivas, representadas pela linguagem (textos, símbolos, etc.) presente nas interações; (3) episódicas, relacionadas às práticas que criam oportunidades para a interação e coordenação dessas interações. Por fim, os praticantes referem-se aos tradicionais estrategistas da alta administração, mas também englobam os demais sujeitos da organização (Whittington, 2006).

Assim, de modo geral, esperamos que os discentes tenham assimilado que ao compreender os padróes de ação transmitidos pelas práticas, a $\mathrm{S}$-as-P possibilita pensarmos os problemas de comunicação interna e divisão de funções e tarefas de forma invertida. Ao invés de pensarmos que há um problema da organização em adequar os fluxos de comunicação e a divisão de tarefas em um registro formal, deve-se tomar os padrões rotinizados, ou o feixe de práxis (ou ainda os modos de pensar, falar e fazer) na FIS, como fonte de informação e adequação para os registros formais dos mecanismos de comunicação interna e das divisões de tarefas. Essa inversão, baseada no ajuste mútuo entre os registros formais e o que acontece no cotidiano da organização, pode auxiliar no conhecimento das coordenações sobre as atividades de outros atores e minimizar ou regular os conflitos de atribuição. Da mesma forma, a comunicação pode ser pensada em termos de interação (ou falta de interação) entre as coordenações e a gestão, devendo à gestão a responsabilidade de encontrar meios de facilitar essa interação e torná-la algo comum ao cotidiano organizacional.

\section{Terceira questão:}

É bom lembrar, logo de partida, a especificidade da compreensão da S-as-P sobre a comunicação organizacional, frente a abordagens tradicionais no campo de Gestão e mesmo diante do senso comum a respeito dessa expressão. Rese, Casali e Canhada (2011) lembram-nos, oportunamente, que a comunicação deve ser compreendida como um processo produtor de sentidos e significados que emerge nas interações linguísticas e simbólicas que permeiam a prática estratégica. Sob esta perspectiva, a análise da comunicação, por meio das controvérsias que ela produz, oferece-nos um locus privilegiado e rico em possibilidades para a compreensão das múltiplas lógicas acionadas no fazer cotidiano. Assim, os desafios comunicacionais, como compreendidos pela $S$-as-P, estão muito além de resoluções meramente instrumentais, como a adoção de ferramentas mais eficientes, por exemplo. Para a S-as-P, a estratégia se dá na linguagem, pois são as narrativas que dão sentido à prática.

Nesse sentido, prescrever soluções para a resolução do problema de comunicação e de divisão das tarefas, sem compreender os fluxos comunicacionais que fundam o cotidiano da organização - lembremos que, na perspectiva da $\mathrm{S}$-as-P, os indivíduos criam ativamente o seu mundo na medida em que estão imersos nas interações sociais -, pode comprometer qualquer resolução apresentada. Portanto, não é possível desenhar um plano estratégico de comunicação sem conhecer a pluralidade de disputas narrativas no cotidiano.

Sugere-se, portanto, que as soluções formuladas pelos alunos sejam discutidas a partir das evidências do caso, estimulando a apresentação de possibilidades de resolução dos problemas por meio de um exercício simulado. Uma alternativa bastante profícua nesta direção é a realização de uma encenação do caso pelos discentes. A dramatização proporcionada pela teatralização de um dilema real vivido pelo personagem Jonas é um caminho potente para inserir os estudantes no contexto experimentado pelo protagonista. Cada grupo pode encenar uma solução para o problema apresentado e, ao final, o docente articula as estratégias surgidas, acentuando a complexidade da questão e as virtudes das soluções geradas coletivamente. 
Outro caminho oportuno é trabalhar a abordagem da Comunicação Não-Violenta (CNV), desenvolvida pelo psicólogo social Marshall B. Rosenberg e compilada em seu livro "Comunicação Não-Violenta: técnicas para aprimorar relacionamentos pessoais e profissionais”, publicado no Brasil em 2006. A CNV é uma metodologia de aprimoramento das relações interpessoais que tem como ponto de partida o estímulo da expressão autêntica dos envolvidos no processo comunicativo, para que possamos construir acordos de convivência capazes de respeitar interesses e valores mínimos que cada parte deseja preservar numa relação pessoal e (ou) profissional. A CNV parte do princípio de que, para lidar com as controvérsias comunicativas, é necessário que os falantes expressem o que sentem e pensam, considerando quatro atributos que, via de regra, estão implícitos nas conversações e podem ser a causa de vários problemas - são os não-ditos do processo comunicativo. A partir daí, Rosenberg (2006) propõe um modelo da CNV composto por quatro componentes, isto é, por quatro atitudes que possibilitam a melhora da qualidade das relações:

- Observar sem avaliar e (ou) julgar: o primeiro componente sugere que observemos, sem acrescentar avaliação, o que vemos, ouvimos, tocamos que afeta nossa sensação de bem-estar;

- Identificar e expressar sentimentos: quais sentimentos surgem em mim diante de um conflito, diante de uma atitude de outra pessoa, diante de uma situação que vejo e acho que não está correta? A proposta aqui é identificar esses sentimentos, respondendo à pergunta: como nos sentimos em relação ao que estamos observando?

- Identificar necessidades não atendidas: diante de um sentimento que emergiu em uma das situações citadas acima, é importante reconhecer qual necessidade básica eu gostaria que fosse atendida, mas não está sendo, isto é, quais necessidades, valores, desejos não atendidos são as geradoras dos sentimentos?

- Pedido: o que gostaríamos que a outra pessoa - ou os vários envolvidos - faça para resolver ou mitigar aquela situação?

Rosenberg (2006, p. 25) cita um exemplo simples, num tom didático, para que nos familiarizemos com esses componentes numa conversação cotidiana:

"Uma mãe poderia expressar essas três coisas ao filho adolescente dizendo, por exemplo: 'Roberto, quando eu vejo duas bolas de meias sujas debaixo da mesinha e mais três perto da TV, fico irritada, porque preciso de mais ordem no espaço que usamos em comum'. Ela imediatamente continuaria com o quarto componente - um pedido bem específico: 'Você poderia colocar suas meias no seu quarto ou na lavadora?'. Esse comportamento enfoca o que estamos querendo da outra pessoa para enriquecer nossa vida ou torná-la mais maravilhosa"

O modelo acima pode ser utilizado pelos estudantes, a partir das informaçóes presentes no caso, o que daria um ponto de partida substantivo para explorar soluções para os dilemas da FIS.

Referencial complementar para os docentes:

- Recomenda-se a leitura de Rosenberg (2006), pelo menos o capítulo 1, mas é desejável a leitura até o capítulo 6 e, num cenário ideal, a leitura da obra;

- Recomenda-se ainda, caso haja necessidade de ter contato com uma abordagem teórica sobre o entendimento da comunicação organizacional sob o ponto de vista da S-as-P, o artigo de Rese et al. (2011), mas entendemos que não é uma leitura prioritária.

- Recomenda-se ainda, caso haja necessidade de ter contato com uma abordagem teórica sobre o entendimento da comunicação organizacional sob o ponto de vista da S-as-P, o artigo de Rese et al. (2011), mas entendemos que não é uma leitura prioritária. 


\section{Quarta questão:}

A estratégia como prática enfatiza a ação estratégica como um evento situado no tempo e no espaço, isto é, um comportamento construído socialmente nas interações - marcadas por assimetrias de poder - entre os sujeitos que trazem consigo vínculos históricos (Jarzabkowski \& Spee, 2009). O entendimento da S-as$\mathrm{P}$ é que as organizações são produzidas e reproduzidas continuamente e devem ser entendidas como um feixe de práxis. Esse feixe é constituído por elementos como tecnologias, rotinas, objetos, ideias, lógicas de pensamento, etc. Os praticantes são tanto os tradicionais estrategistas da alta administração quanto os demais sujeitos da organização (Whittington, 2006). Portanto, compreender suas práticas e os padrões rotinizados que constituem a ação coletiva na FIS é fundamental para a construção de um plano estratégico participativo.

Independente de formalização, é necessário compreender que já há uma estratégia, ou estratégias, acontecendo na FIS desde o momento de sua criação. As interações diárias e o cotidiano da organização evidenciam diferentes maneiras de fazer que estão "dentro" dos processos organizacionais e subordinam processos e agentes da organização. As práticas transmitem uma lógica para ação. Por exemplo, quando observamos a Figura 2, nota-se que diferentes atores possuem diagnósticos distintos para os problemas da FIS e cada um deles guarda uma coerência interna, isto é, surgem a partir de uma visão particular de mundo (um diagnóstico particular) e, por sua vez, geram uma série de ações, comportamentos, interpretações e demandam recursos específicos. As falas dos entrevistados, na Figura 2, não são trechos deslocados do contexto. Elas devem ser compreendidas como enunciados capazes de revelar padróes de pensar e agir, são indicadores da racionalidade intrínseca da organização. Quando esses múltiplos enunciados se relacionam, surgem tensões. As tensões são, portanto, manifestações de visões de mundo que precisam ser compreendidas para melhorar a estabilidade da FIS. O docente pode solicitar que o estudante analise esse conjunto de falas, buscando descrever quais padróes elas revelam.

Capturar esse movimento inventivo do cotidiano é fundamental para que o gestor possa compreender as organizações de modo mais sistêmico, incluindo tais maneiras de pensar, falar e fazer no seu "diagnóstico" organizacional e assim propor ações que possibilitem aos atores se sentirem construtores ativos da FIS. Há também a possibilidade de estimular ainda mais os discentes, recomendando que eles proponham como o personagem central conseguirá capturar o cotidiano organizacional. Será que o caminho é realizar rodas de conversas temáticas, dinâmicas de grupo? Como promover a dialogicidade na FIS, reconhecer sua diversidade e considerá-la como combustível para elaboração do plano estratégico? Essas são perguntas-chave que podem ser usadas como direcionadoras para o aprofundamento da questão.

Referencial complementar para os(as) docentes:

- Recomenda-se a leitura de Cruz, Carmo, Ribeiro e Assis (2018). Os autores utilizam referencial teórico similar ao apresentado por nós, enfatizam os praticantes no caso em análise e escreveram um texto clássico que traz uma "aplicação" dos conceitos da estratégia como prática, um posicionamento que acreditamos ser útil para reflexão da situação da FIS;

- Para um texto sensível e crítico, que aborda mais subjetivamente o significado da expressão "capturar o cotidiano organizacional", sugere-se Oliveira e Cavedon (2013).

\section{ReFERÊNCIAS}

Cruz, I. F., Carmo, L. J. O., Ribeiro, J. E., \& Assis, L. B. (2018). Estratégia como prática para o enfrentamento da crise hídrica: Um olhar para os praticantes. Revista de Administração, Sociedade e Inovação, 4(2), 140-159.

Jarzabkowski, P. (2005). Strategy as practice: An activity-based approach. London: Sage. 
Jarzabkowski, P., Balogun, J., \& Seidl, D. (2007). Strategizing: The challenges of a practice perspective. Human relations, $60(1), 5-27$.

Jarzabkowski, P., \& Paul Spee, A. (2009). Strategy - as - practice: A review and future directions for the field. International Journal of Management Reviews, 11(1), 69-95.

Nicolini, A. (2003). Qual será o futuro das fábricas de administradores? RAE-Revista de Administração de Empresas, 43(2), 44-54.

Oliveira, J. Silva de, \& Rolita Cavedon, N. (2013). Micropolíticas das práticas cotidianas: etnografando uma organização circense. RAE-Revista de Administração de Empresas, 53(2), 156-168. http://dx.doi.org/10.1590/ S0034-75902013000200004

Rese, N., Casali, A. M., \& Canhada, D. I. D. (2011). Reflexões iniciais sobre comunicação organizacional na abordagem da estratégia como prática social. Gestão e Sociedade, 5(10), 42-56.

Rosenberg, M. B. (2006). Comunicação não-violenta: técnicas para aprimorar relacionamentos pessoais e profissionais. São Paulo: Editora Ágora.

Whittington, R. (2006). Completing the practice turn in strategy research. Organization studies, 27(5), 613-634. 